\title{
Willingness to Pay for Eco-Labeled Food in Forests: Integrated View from South Korea
}

\author{
Jang-Hwan Jo ${ }^{1,+}$, Ji Yeon Yang ${ }^{2, \dagger}$ and Taewoo Roh $^{3, *}$ (i) \\ 1 School of Geography and the Environment, University of Oxford, South Parks Road, Oxford OX1 3QY, UK; \\ osmanthusfvam.jo@ouce.ox.ac.uk \\ 2 Department of Global Business, The University of Suwon, Business School 810, 17 Wauan-gil, Bongdam-eup, \\ Hwaseong-si 18323, Gyeonggi-do, Korea; jiyyang@suwon.ac.kr \\ 3 Department of International Trade and Commerce, Soonchunhyang University, Unitopia 901, \\ Soonchunhyang-ro 22, Sinchang-myeon, Asan-si 31538, Chungchungnam-do, Korea \\ * Correspondence: troh@sch.ac.kr \\ + Both authors contributed equally to this paper.
}

Received: 28 August 2019; Accepted: 19 November 2019; Published: 20 November 2019

\begin{abstract}
Due to global interest in the improvement of national income and quality of life, eco-labeled food (ELF) for sustainable consumption and personal healthcare has been increasing. This study aims to contribute to two research streams by examining the quality of ELF in forests (ELFF). First, this study intends to estimate the willingness to pay (WTP) of ELFF producers for the certification verified by the government-supported institution and investigate the difference in certification costs between the actual certificating authority and ELFF producers. Second, this study aims to figure out the perception mechanism of how consumers who would like to purchase ELFFs recognize the effect of enhanced certification. These efforts may contribute to the research on how to raise interest in the production of ELF-related products and sustainable consumption. To achieve the purpose of this study, we adopted contingent valuation methods (CVM) to measure WTPs using interview-based surveys with 40 ELF producers and ordinary least squares (OLS) regression to examine the effect of certification with 112 consumers who experienced ELF consumption. Results of this study provide theoretical and practical implications by looking at the relationship between ELF certification and sustainable consumption from a stakeholder's perspective. This study intends to expand the research field of ELF from agriculture to forestry products. It provides a basis for providing practical implications for policymakers who propose sustainable consumption.
\end{abstract}

Keywords: contingent valuation methods; eco-labeled food; willingness to pay; sustainable consumption

\section{Introduction}

Recently, international interest in eco-labeled food (ELF) as a safe food for health promotion has been increasing due to improved national income and improved quality of life [1]. For example, Grankvist and Biel [2] have found that consumers who buy ELFs consider both health and the environment as important and that those who have purchased similar products with eco-labels in the past have a higher frequency of purchasing ELFs. In the analysis of Chinese consumers' perception of eco-labeled rice, Liu et al. [3] have also found that it is important to accurately convey health information of eco-labels because consumers struggle between price premiums and food safety. While the production of agricultural products is continuously increasing due to technological development, production conditions of forest products are mainly made up of small or coarse cultivation, making it challenging to professionally distribute and generate income. In particular, forest products are cultivated under harsh conditions. It is difficult to distinguish them from general agricultural products. 
Forest products are also less likely to be picked by consumers and receive competitive pay because the quality of forest products is not yet certified [4-6]. Moreover, while forest products are produced with higher production costs than the agricultural products, forest product producers receive a lower income than agricultural product producers. Indeed, the average income level of forestry households is lower than that of the primary industry group and urbanites [7].

This study proposes that certification is a way to enhance consumers' awareness of ELF for sustainable consumption of ELFF. This study also provides suppliers with differences between the cost required to operate the actual certification system and willingness to pay (WTP) [8]. In addition, based on a comparison with other certifications, we verify the perception of distribution specialists and consumers for sustainable ELF consumption. In other words, this study aims to derive some theoretical/practical implications for sustainable consumption of ELF from the perspective of direct stakeholders surrounding ELF.

Certification is a scheme in which the third party that secures public confidence evaluates the quality or ability of a product consistently, demonstrating its compliance with prescribed standards or excellence in quality [1,5]. Firstly, certification increases producers' income by increasing advertising effectiveness by differentiating certified produtcs from other products, and by reducing sales and distribution costs through the formation of consumer confidence [9]. Secondly, distributors (vendors) can also obtain improved operating profit by facilitating quality control through certification [10]. Thirdly, through ELF certification, consumers can quickly determine the authenticity of products that are difficult to identify directly $[1,10,11]$. While previous studies on certification have focused on International Standards Organization (ISO)-focused industrial products, this study deals with methods such as Eco-friendly Agricultural Products Certification, Good Agricultural Practices (GAP) certification and hazard analysis critical control point (HACCP). This study also discusses the possibility of sustainable consumption through ELF certification.

This study aims to contribute significantly to two research flows by studying high-quality ELF grown in forests. Firstly, suppliers of ELFs preferably want certification but are hesitant to receive it due to certification costs. Farming houses or leasing houses that produce ELFs require considerable attention and effort compared to producers who use high amounts of chemical fertilizers. It takes a long time to achieve successful commercialization of ELFs [12]. Thus, ELF producers tend to increase their sales costs due to a strong desire to recoup costs invested in product development over a long period, making it difficult to commercialize them in many cases. It is the certification cost that has a decisive effect on the selling costs determined by the ELF producer. Therefore, this study attempts to estimate the willingness to pay (WTP) that an ELF producer can present for certification and to verify the difference in certification costs presented by the actual certificating authority [13]. Second, it is necessary to raise awareness of the certification for consumers who wish to purchase ELFs. GAP standards have been discussed several times in the World Trade Organization multilateral discussions to raise awareness that the world has the right food for decades [14]. In short, ELF certification, which has been mainly focused on agricultural products, can be further expanded by identifying consumers' awareness, satisfaction, purchase and payment intentions for forest products.

\section{Literature Review and Hypothesis Development}

\subsection{Regulation on Certification for ELF}

Studies related to environmentally friendly agricultural products (ELF in agriculture, ELFA) have investigated the ELFA purchasing behavior of consumers who focus on consumers who consume ELFA mostly. Previous studies have also analyzed the ELFA certification system itself. These studies have focused on consumer purchasing behavior and ELFA consumption. Kim et al. [15] have presented the direction of improving the ELFA system by analyzing the utilization situation related to ELFA, how to obtain information about ELFA and satisfaction after purchase. 
Nam and Noh [16] have reexamined implications of ELFA by analyzing consumers' consumption behaviors in response to uncertain product information. Lee et al. [17] have analyzed the current status and purchasing pattern of consumers using ELFA. They also examined the effect of purchasing ELFA on consumers' attitude variables such as the perception of environmentally friendly agricultural products and interest in health $[18,19]$. Kim et al. [20] have found that consumers are reluctant to buy ELFA because the price is too high (74.3\%), indicating that the price of ELFA is the biggest obstacle to the expansion of the consumption of ELFA. According to a survey conducted by Lee, Kim, Heo, Lim, Kim and Park [17], 46\% of respondents did not purchase ELFAs despite consumers having a high level of interest in health. Consumers, regardless of income level, purchased a low proportion of ELFAs due to barriers both at price premium and asymmetry information on the certification.

Meanwhile, the status of the ELFA accreditation system [21] and ways to improve the ELFA certification system [22] have been determined by analyzing the ELFA system itself. As suggested by Janssen and Hamm [10], certification is a powerful tool to persuade consumers to purchase ELFA, assuming that the certification mark plays an essential role in making consumers trust the products.

\subsection{Certification on Agriculture}

GAP was introduced in 2003 and implemented after 2006. To preserve the agricultural environment and ensure the safety of agricultural products, GAP carries out production, harvesting and post-harvest management (storing, washing, drying, sorting, cutting, preparing and packing) of agricultural products [23]. It also refers to proper management of agricultural chemicals, heavy metals, persistent organic pollutants or harmful organisms that may remain in agriculture and agricultural products such as agricultural land and agricultural water where crops are cultivated at each stage of distribution. In particular, GAP is designed to provide safe agricultural and livestock products to consumers by establishing a safety management system for farm products from the production stage to the sales stage [14].

The number of items for GAP certification and traceability management registration has been expanded to 105. These items are cultivated for domestic use. To settle the system, four strategies were established for the promotion of an organization, production expansion, distribution promotion and sales expansion after the project was initiated in earnest [23]. When the GAP system was first introduced in South Korea, systematic proposals such as preparation of management regulations, the establishment of hygiene infrastructure, development of guidelines for cultivation and management and the preparation of educational systems were implemented. However, there were problems such as the lack of understanding of farmers' systems, the burden of examination costs and the lack of awareness of consumers [24]. To solve these problems, the government consolidated risk management, including integrating certification procedures, realizing GAP certification standards and strengthening consulting so that they could be post-managed. Certification marks provided by the representative certification operated by the Ministry of Agriculture, Food and Rural Affairs and by Korea Forestry Promotion Institute (KOPFI) are shown in Table 1.

Table 1. Eco-labeled food (ELF) in agriculture and forestry.

\begin{tabular}{|c|c|c|c|c|c|c|}
\hline Field & & Agricu & 1lture & & Forestry & Source \\
\hline Type & Organic & Non-Pesticide & Non-Antibiotic & $\begin{array}{c}\text { Organic } \\
\text { Processed }\end{array}$ & Organic & $\begin{array}{l}\text { EAPC [25] } \\
\text { KOPEI [2] }\end{array}$ \\
\hline $\begin{array}{c}\text { Certified } \\
\text { Mark }\end{array}$ & $\begin{array}{l}\text { ORGANIC } \\
\text { MAFRA KOREA }\end{array}$ & $\begin{array}{c}\begin{array}{c}\text { NON } \\
\text { PESTICIDE }\end{array} \\
\text { MAFRA KOREA }\end{array}$ & $\underbrace{\begin{array}{c}\text { NON } \\
\text { ANTIBIOTIC }\end{array}}_{\text {MAFRA KOREA }}$ & ORGANIC & & \\
\hline
\end{tabular}

Note: Environment-friendly Agricultural Products Certification (EAPC), KOPFI. 


\subsection{Certification on ELF in Forestry}

\subsubsection{Supply Side: WTP}

Certification of ELF in forestry (ELFF) in the international community began in the early 2000s with the expectation of sustainable development of local forestry and income generation of people through niche markets $[9,27]$. Experts believe that forest certification plays a major role in commercializing forest products by enabling producers to produce responsibly and to facilitate market access $[4,28]$. According to Shanley, Pierce, Laird and Robinson [4], the main goal of the ELFF certification is to produce ELFF that is ecologically sound, create social profits and ensure economic viability. Pierce et al. [29] have analyzed the effect of market-based certification systems on communities and producers for ELFF produced in mountain villages.

Wilsey and Radachowsky [12] have analyzed forest areas of the Maya Biosphere Reserve and found that ELFF certification is economically feasible because it provides local forest workers with the commercialization of ELFF products. Schmitt, Pokorny and Ying [13] have reported that China has technological and financial resources to produce, manage and monitor ELFF products. However, they find that the role of ELFF is minimal. Since it is more attractive to meet certification requirements for crops and cropped ELFFs than ELFFs, the need to certify general ELFFs is minimal. They also stated that without the help of an outside organizations, small-scale poor tenants and peasants would have difficulty getting the real benefits. Without intensive and sustained support for them, China's efforts on ELFF could even destroy the traditional ELFF market.

Meanwhile, Guedes Pinto, Shanley, Cota Gomes and Robinson [6] reported that certification of forest management through the Forest Stewardship Council (FSC) began in the 1990s after non-governmental organizations (NGOs), communities, private sector, researchers and governments began to carry out efforts to certify ELFFs. The certification focused only on wood. Brazil played an important leadership role in the process. In their paper, Brazil's certification cases, public policy and success factors for the ELFF process of the FSC are presented. Similarly, Pierce, Shanley and Laird [29] have introduced some difficulties and successes that ELFF producers face in obtaining certification based on their eight-year experience with the FSC. Accordingly, ELFF is part of a low-value product family with a low margin that requires a lot of labor input but with a low valued product, resulting in an low level of the economy scale. Thus, it may be difficult for the supply of ELFF to keep up with the market demand. In addition, it threatens the existing market with an oversupply of uncertified, inexpensive products. Thus, this study has the following hypothesis:

Hypothesis H1. While ELF contributes to sustainability, ELF producers hesitate to pay for certification as much as the market expects.

\subsubsection{Demand Side: Satisfaction}

Suppliers are obliged to pay the certification fee for ELF [10]. Most costs will be burdensome for small forest product providers [7]. However, since an ELF can contribute to sustainability, it is worth looking at how certification is delivered to buyers. ELF providers may be reluctant to produce ELFs because of the cost of certification. However, if consumers are fully aware of this and intend to purchase, the marketability will require a long-term investment $[7,30]$. In other words, from a supplier's perspective, the WTP should come up with some solutions to the uncertainty about certification. Furthermore, efforts have been made in many countries to introduce a forestry product certification system, going beyond the focus of wood certification only since the 2000s [12,31]. Positive responses are prevalent. For example, a market tool called a certification system is introduced. It allows non-timber forest products to be managed under more social and environmental responsibility and relieves anxiety about food on the part of consumers. It is becoming a more eco-friendly yet healthy source of so-called sustainable consumption [32]. 
Duchelle, Kainer and Wadt [5] have compared and analyzed environmental and socioeconomic benefits of Brazil's nut certification to 231 producers of 17 local communities in Bolivia, Brazil, and Peru from 2006 to 2007. Differences in management methods between certified and uncertified producers concerning ELF were compared and analyzed. Socio-economic benefits of certified ELF were then investigated. Finally, producers' awareness of ELF certification was investigated. Producers earned financial and social profit in the following order: Bolivia, Peru and Brazil. Their study argues that partnerships with co-operatives, donors, governments and non-governmental organizations are essential for preserving ecosystems through certification and maximizing the production goal.

Krishnakumar et al. [33] have surveyed 101 households in India's Kadars region to identify the extent of social and economic dependence of ELFs on households in the Karar region and performed a comparative analysis of market values that ELFFs have on the Kadars region as a post-certification reward under current market conditions. Their study performed a scenario analysis after dividing the certification area by 500 ha, 1000 ha and 2500 ha, estimating that the annual profit from the current status is 405.7 dollars. Their study also estimated the annual profit margin that could be obtained after the certification, and found that there was a price premium of $35 \%$ or more of the profit.

Yadav and Dugaya [34] have found that ELFF certification is a marketing tool to appeal to environmentally conscious consumers to sustainably manage healthy forests. It is mainly due to social concerns about the social and environmental significance of forests. ELFFs have played an essential role in social, economic and cultural life for mountain-dwelling residents of countries with tropical rain forests such as India. Certification has covered more than 46,000 different species, with varying local access to these ELFFs, usage methods, commercialization, management practices and policies. In other words, if the consumption of ELFF consistently benefits producers by emphasizing that it is a safe food for consumers and making forests sustainable at the same time, the certification's contribution to sustainability would be significant.

According to research on the Korean market, which is the subject of the present study, Heo et al. [35] have concluded that consumers value certified peaches two-thirds more than non-certified peaches. In an analysis of consumers' willingness to pay for genetically modified agricultural products and general agricultural products that have potential risks to ecosystems and health, Kwon [36] has found that the intention to pay for general agricultural products is twice as much as that of genetically modified agricultural products. According to Shukri and Awang Noor [8], although existing studies had shown a growing demand for certified wood products in developing countries, most of the demand for certified products is in North America or in European countries where there is room for environmental and ethical recognition. A study was conducted in Kuala Lumpur on whether consumers in Malaysia, which produces and exports certified wood products, paid a price premium for environmentally certified wooden furniture. That study showed that if the majority of respondents $(74 \%)$ became aware of certification, they would purchase certified products rather than uncertified products [8]. The above findings show that consumers with a higher awareness of certification are more willing to purchase certified products.

Meanwhile, Kim, Lee and Sok [15] have studied housewives and analyzed the status of their use related to certified products and the methods, satisfaction and intent to obtain information on ELFA to suggest the direction for improvement of the ELFA system. They found that the ease and satisfaction of obtaining information on ELFA had a positive effect on purchasing intent. Nam and Noh [16] have proposed a certification system as a form of response to uncertain product information. The consumption of certified products can increase consumer satisfaction by eliminating the uncertainty. Lee et al. [37] have analyzed consumers' status and purchasing patterns using ELFA. They found that consumers' attitudes, such as awareness of eco-friendly agricultural products and concerns about health enhanced their satisfaction with certified products and affected their purchase of ELFA. Shukri and Awang Noor [8] also claimed that certified wood products showed a high level of satisfaction with consumers' use. They reported that consumers were willing to pay about $18 \%$ more for certified ELFF than for their competitors not certified for ELFF. The above findings show that consumers who are 
more satisfied with certification are more likely to purchase certified products. Thus, this study has the following hypothesis:

Hypothesis H2. Consumers with higher awareness of ELFA will be more willing to purchase ELFF.

Hypothesis H3. Consumers with higher satisfaction of ELFA will be more willing to purchase ELFF.

\section{Methodology}

\subsection{Samples}

The subjects of this study were 40 ELFF suppliers and 112 consumers who had experienced ELF consumption. A face-to-face interview with suppliers and an Internet survey on consumers were performed. We aim to contribute to the research stream of sustainable consumption by activating ELF and by raising the awareness of producers who want to produce ELFF but are hesitant due to certification costs and customers who are not aware of ELF, which may be better for healthcare than non-environmentally friendly food $[10,11]$. To address our research question, we conducted face-to-face surveys with ELFF suppliers and online surveys with customers over three months. Interviews with 40 ELFF producers were conducted at an annual meeting hosted by KOPFI, the only institution that certified Korean ELFF. In 2018, although KOPFI granted authorization to a total of 44 ELFF companies, 40 were able to implement the estimation for WTP. Four suppliers were excluded for personal reasons [38]. A consumer awareness survey on ELFF was conducted by snowball sampling [8]. Each researcher who participated in this study used QR and link recommendations to secure various customer groups using a social network service. The response rate was $60 \%$, which was somewhat reliable.

The process of estimation of CVM and OLS regression comined is shown in Figure 1. CVM focuses on WTP by ELF producers for a certification fee determined by the certification institution while OLS looks into the impact of various factors to attract consumers' interest in ELFs.

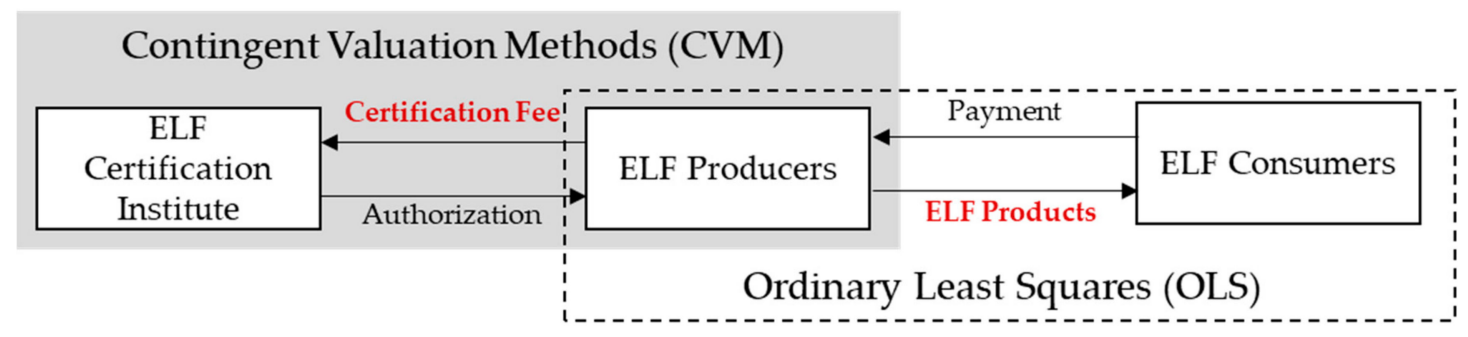

Figure 1. Conceptual estimation process.

\subsection{Contingent Valuation Method}

Double-bounded dichotomous choice CVM (DCVM) is a method in which respondents strategically exaggerate or shrink the compensation surplus to respond to their bids, such as bidding games, open questions and payment card methods, thereby considerably reducing the possibility of strategic convenience [10,38]. As measurement tools for DCVM, a random utility model, a logistic regression model and a Turnbull model are mainly used to estimate WTP $[35,39,40]$. Both the random utility model and the logistic regression model can estimate the respondent's payment intention using a parametric method that takes into account the assumed function form in advance. As an alternative to such problems, Turnbull, a distribution-free model, is introduced as a nonparametric approach. In this study, since there was a limit in the number of ELFF suppliers to be investigated and it was difficult to carry out an analysis including explanatory variables consistently, we adopted Haab and McConnell's [38] Turnbull model, assuming nonparametric distribution to estimate the utility of producers in the ELF certification system. 


\subsection{Ordinary Least Square (OLS) Regression}

The most commonly used model for explaining the relationship between one or more independent variables and dependent variables is OLS regression. Linear regression analysis is useful for assessing the effect of independent variables on a dependent variable including constant terms. The estimation becomes more precise when control variables that can reduce the distortion between variables are added. In this study, ELFF purchase intention was used as a dependent variable, while ELFA awareness and satisfaction were selected as independent variables after controlling for respondents' age, gender, family size, the presence of infants in the family and whether the respondent was a full-time mother in the household [10,11].

\subsection{Variables}

To assess the WTP of ELFF producers, we asked them for a firm's representative of demographic characteristics such as gender, age and region. According to Haab and McConnell [38], we designed a multi-layer of price bid for WTP. For comparing three kinds of WTP using "yes" or "no," the most favorable price bid, the most favorable price bid range and the lower bounded price bid were asked for. All bids for WTP were recommended by experts whom we had interviewed. To achieve the expected value for WTP, we set up the bid as 150,000 Korean Won (KRW), 300,000 KRW and 600,000 KRW. After that, by using the probability density function (PDF) and cumulative density function (CDP), another expected value for WTP was drawn from 0 to 350,000 KRW. WTP by Turnbull estimation ranged from 0 to 300,000 KRW [36].

To conduct OLS regression, we controlled a consumer's demographics such as age, gender, number of family members, whether there were infants in the family and full-time mother [41]. Another control variable was the extent to which consumers were aware of ELFF (AELFF) before. It was measured with a five-point Likert scale [8]. Our dependent variable was a consumer's purchase intention for ELFF (PELFF). It was measured with a five-point Likert scale $[8,41]$. Explanatory variables were as follows. First, awareness of ELFA (AELFA), meaning how much consumers were favorably aware of ELFA measured with a five-point Likert scale. Second, the satisfaction of ELFA (SELFA), meaning how much consumers were satisfied with ELFA measured with a five-point Likert scale [11,18].

\section{Results}

\subsection{Descriptive Statistics}

Panel A in Table 2 shows the basic statistics for suppliers. Among suppliers, there were 36 men $(90 \%)$ and 4 women $(10 \%)$. The most common age group was in their $60 \mathrm{~s}(\mathrm{n}=18,45 \%)$, followed by those in their $50 \mathrm{~s}(\mathrm{n}=13,32.5 \%)$ and $40 \mathrm{~s}(\mathrm{n}=7,17.5 \%)$. By region, Gangwon-do had the highest number of people $(n=13,32.5 \%)$, followed by 7 people $(17.5 \%)$ in North Chungcheong and 5 people $(12.5 \%)$ in South Chungcheong. Panel B in Table 2 shows basic statistics for consumers. Of 112 consumers, 45 were men and 67 were women. By age group, there were $25(22.32 \%)$ consumers in their $20 \mathrm{~s}, 24$ in their 50s, 23 in their 60s or older, 19 in their 40s and 21 in their 30s. Regarding the number of family members, one person had the highest percentage $(n=33,9.46 \%)$. Regarding the consumers' families, 55 households had no children while 57 households had children. Moreover, housewives who did household chores in consumers' homes were mostly not full-time. 
Table 2. Descriptive statistics for supplier and consumer.

\begin{tabular}{|c|c|c|c|}
\hline \multicolumn{4}{|c|}{ Panel A: Supplier } \\
\hline Variable & Category & Frequency $(\mathrm{N})$ & Percentage $(\%)$ \\
\hline \multirow{2}{*}{ Gender } & Male & 36 & 90 \\
\hline & Female & 4 & 10 \\
\hline \multirow{5}{*}{ Age } & $20 \mathrm{~s}$ & 1 & 2.5 \\
\hline & $30 \mathrm{~s}$ & 1 & 2.5 \\
\hline & $40 \mathrm{~s}$ & 7 & 17.5 \\
\hline & $50 \mathrm{~s}$ & 13 & 32.5 \\
\hline & $60 \mathrm{~s}$ & 18 & 45 \\
\hline \multirow{8}{*}{ Region } & Gyunggi Province & 3 & 7.5 \\
\hline & Gangwon Province & 13 & 32.5 \\
\hline & South Chungcheong Province & 5 & 12.5 \\
\hline & North Chungcheong Province & 7 & 17.5 \\
\hline & South Jeolla Province & 2 & 5 \\
\hline & North Jeolla Province & 2 & 5 \\
\hline & South Kyungsang Province & 4 & 10 \\
\hline & North Kyungsang Province & 4 & 10 \\
\hline \multicolumn{2}{|c|}{ Total } & 40 & 100 \\
\hline \multicolumn{4}{|c|}{ Panel B: Consumer } \\
\hline Variable & Category & Frequency (N) & Percentage $(\%)$ \\
\hline \multirow{2}{*}{ Gender } & Female & 67 & 59.82 \\
\hline & Male & 45 & 40.18 \\
\hline \multirow{5}{*}{ Age } & $20 \mathrm{~s}$ & 25 & 22.32 \\
\hline & $30 \mathrm{~s}$ & 21 & 18.75 \\
\hline & $40 \mathrm{~s}$ & 19 & 16.96 \\
\hline & $50 \mathrm{~s}$ & 24 & 21.43 \\
\hline & $>60 \mathrm{~s}$ & 23 & 20.54 \\
\hline \multirow{5}{*}{ Number of family } & 1 & 33 & 29.46 \\
\hline & 2 & 25 & 22.32 \\
\hline & 3 & 29 & 25.89 \\
\hline & 4 & 23 & 20.54 \\
\hline & $>5$ & 2 & 1.79 \\
\hline \multirow{2}{*}{ Infants in family } & No & 55 & 49.11 \\
\hline & Yes & 57 & 50.89 \\
\hline \multirow{2}{*}{ Full-time mother in family } & No & 102 & 91.07 \\
\hline & Yes & 10 & 8.93 \\
\hline \multicolumn{2}{|c|}{ Total } & 112 & 100 \\
\hline
\end{tabular}

\subsection{Double-Bounded Dichotomous Choice: Turnbull}

Producers' WTPs for the ELF estimated by this study are presented in terms of expected value, cumulative distribution function, and nonparametric approach using the Turnbull model. First, the WTP for estimating the average expected value of the presented amount had the supplier select yes or no for the suggested amount. The value for yes and its frequency value were averaged by summing up the total. This study interviewed ELF experts and found that reasonable ELFF costs were divided into 150,000 KRW, 300,000 KRW and 600,000 KRW. Accordingly, all ELFF suppliers in South Korea requested a response to the survey because they had to be certified by KOPFI. As a result, the mean annual WTP for ELFF suppliers willing to pay was 156,194 KRW (see Table 3). 
Table 3. Expected value for willingness to pay (WTP).

\begin{tabular}{cccc}
\hline First bid & Frequency (No) & Frequency (Yes) & Expected Value \\
\hline 150,000 & 15 & 3 & 25,000 \\
300,000 & 5 & 17 & 231,818 \\
600,000 & 11 & 6 & 211,764 \\
& & & 156,194 \\
\hline
\end{tabular}

Participation in each first bid was random. Thus, the total number of participants was designed to exceed 40 people. Next, the expected value of WTP was estimated using the probability density function and the cumulative distribution function according to the range of the presented amount for the ELFF. The increase in the suggested amount was 50,000 KRW, which was similar to the section used for agricultural product certification costs. There was no response to the 250,000 KRW section, which is excluded from the table. The cumulative distribution function (CDF) represents the probability that a random variable is less than or equal to a certain value. It allows us to express the probability of a continuous random variable. The probability density function (PDF) is defined as a derivative function of CDF. It is defined by dividing a specific interval based on the probability from a specific random variable value to a specific interval. The annual WTP for producer-based ELFF, estimated by CDF and PDF, was found to be $135,000 \mathrm{KRW}$ according to the range of the presented amount (see Table 4).

Table 4. Expected value for WTP using the probability density function (PDF) and the cumulative distribution function (CDF).

\begin{tabular}{ccccc}
\hline Bid range & Frequency & PDF (\%) & CDF (\%) & Expected Value \\
\hline 0 & 13 & 32.5 & 32.5 & 0 \\
50,000 & 3 & 7.5 & 40 & 150,000 \\
100,000 & 3 & 7.5 & 47.5 & 300,000 \\
150,000 & 5 & 12.5 & 60 & 750,000 \\
200,000 & 7 & 17.5 & 77.5 & $1,400,000$ \\
300,000 & 7 & 17.5 & 95 & $2,100,000$ \\
350,000 & 2 & 5 & 100 & 700,000 \\
& & & & 135,000 \\
\hline
\end{tabular}

The Turnbull model is the most recent analysis method for evaluating the value of non-market goods [35]. It is possible to estimate both cumulative probability and interval probability distributions. To calculate the section area between the presented amounts, it was essential to first determine what the amount in the probability section was based on. In general, a lower-bound based on the minimum value is applied in each section. The annual WTP for the ELF certification of producers estimated by the Turnbull model, which could be judged to be more sophisticated than the above method, was 193,050 KRW. In Table 5, the WTP that producers had for ELFF was estimated to be 156,194 KRW to 193,050 KRW per year.

Table 5. WTP using Turnbull estimation.

\begin{tabular}{ccccc}
\hline Bid & Lower Bounded Range & Turnbull CDF & Turnbull PDF & Expected Value \\
\hline 0 & $0-150,000$ & 0 & 0 & 0 \\
150,000 & $150,000-300,000$ & 0.833 & 0.833 & 124,950 \\
300,000 & $300,000-600,000$ & 1 & 0.227 & 68,100 \\
& & & & 193,050 \\
\hline
\end{tabular}

\subsection{OLS Regression}

Correlation analysis is an analysis method that can identify the direction and the degree of a relationship by revealing whether the other variable decreases, does not change or increases when one 
variable decreases. The correlation coefficient has a range of -1 to 1 . When the coefficient is close to 1 , there is a strong positive correlation between two variables. When it is close to -1 , it shows a strong negative correlation. In Table 6, AELFF and PELFF showed a significant positive correlation, while SELFA and PELFF also showed a significant positive correlation.

Table 6. Results of correlation analysis.

\begin{tabular}{lcccc}
\hline & $\mathbf{1}$ & $\mathbf{2}$ & $\mathbf{3}$ & $\mathbf{4}$ \\
\hline 1 PELFF & 1.00 & & & \\
2 AELFF & $0.01^{*}$ & 1.00 & & \\
3 AELFA & $0.21^{*}$ & $0.09^{*}$ & 1.00 & \\
4 SELFA & $0.22^{*}$ & $0.06^{*}$ & $0.06^{*}$ & 1.00 \\
\hline
\end{tabular}

Notes: (1) Abbreviations: PELFF = purchase intention for ELFF; AELFF = awareness to pay for ELFF; AELFA $=$ awareness of ELFA; SELFA $=$ satisfaction for ELFA, ELFAA; ELFAS (2) * $p<0.05$

Both AELFA and SELFA showed a positive correlation with PELFF at a significance level of 0.05 ( $\beta=0.21, \beta=0.22$, respectively). Before performing the regression analysis, we used the variance inflation factor (VIF) by estimating the residual variance to determine whether results could be interpreted freely in multiple collinearity problems between independent variables. In general, if the VIF value is lower than 10, there might be no multicollinearity problem and regression analysis can be performed. In this study, VIF had a minimum value of 1.06 and a maximum value of 1.40 . Thus, there was no multicollinearity problem.

Table 7. Result of ordinary least squares (OLS) regression.

\begin{tabular}{|c|c|c|c|c|}
\hline \multirow{2}{*}{ Variables } & \multicolumn{2}{|c|}{ Model 1} & \multicolumn{2}{|c|}{ Model 2} \\
\hline & Coefficient & t-Value & Coefficient & t-Value \\
\hline AELFA & & & $0.26^{*}$ & $(1.97)$ \\
\hline SELFA & & & $0.19^{*}$ & $(2.02)$ \\
\hline AELFF & 0.01 & $(0.08)$ & -0.02 & $(-0.11)$ \\
\hline Age: 30 s & 0.28 & $(0.60)$ & 0.43 & $(0.93)$ \\
\hline Age: 40 s & 0.16 & $(0.33)$ & 0.19 & $(0.40)$ \\
\hline Age: $50 \mathrm{~s}$ & -0.51 & $(-1.09)$ & -0.34 & $(-0.73)$ \\
\hline Age: $>60 \mathrm{~s}$ & -0.08 & $(-0.17)$ & -0.13 & $(-0.29)$ \\
\hline Gender: Female & 0.04 & $(0.11)$ & 0.09 & $(0.29)$ \\
\hline Family number: 2 & 0.33 & $(0.79)$ & 0.43 & $(1.04)$ \\
\hline Family number: 3 & 0.15 & $(0.35)$ & -0.00 & $(-0.01)$ \\
\hline Family number: 4 & -0.23 & $(-0.53)$ & -0.15 & $(-0.36)$ \\
\hline Family number: $>5$ & 1.74 & $(1.49)$ & 1.61 & $(1.39)$ \\
\hline Infants in family: No & 0.22 & $(0.70)$ & 0.13 & $(0.40)$ \\
\hline Full-time mother in family: No & 0.10 & $(0.19)$ & 0.06 & $(0.11)$ \\
\hline Constant & $4.40^{* * *}$ & $(7.45)$ & $2.19^{*}$ & $(2.23)$ \\
\hline Observations & \multicolumn{2}{|c|}{112} & \multicolumn{2}{|c|}{112} \\
\hline$R^{2}$ & \multicolumn{2}{|c|}{0.079} & \multicolumn{2}{|c|}{0.152} \\
\hline adj- $R^{2}$ & \multicolumn{2}{|c|}{0.032} & \multicolumn{2}{|c|}{0.033} \\
\hline Log-likelihood & \multicolumn{2}{|c|}{-201.98} & \multicolumn{2}{|c|}{-197.36} \\
\hline$F$ & \multicolumn{2}{|c|}{$0.71^{*}$} & \multicolumn{2}{|c|}{$1.24^{*}$} \\
\hline
\end{tabular}

As shown in Model 2 of Table 7, the power of explanatory $\left(R^{2}\right)$ was $15.2 \%$ and the model fitness $(F)$ was $1.24(p<0.05)$. Regression results for the consumer recognition survey showed that, although most control variables were insignificant on PELFF, the effect of consumers with AELFA has a positive influence on PELFF ( $\beta=0.26, p<0.05)$. Besides, the effect of consumers' SELFA was positive on $\operatorname{PELFF}(\beta=0.19, p<0.05)$. The coefficient of AELFA was stronger than that of SELFA, indicating that 
consumers might be relatively more sensitive with their awareness than their satisfaction when they were willing to buy ELFFs.

\section{Conclusions and Discussion}

Producers' WTP for achieving the certification of ELFF was estimated to be between 156,194 and 193,050 KRW per year. In the field, each certification requires around 400,000 KRW per year. The investigation management process, which includes a receipt, document review, on-site inspection, production process survey and the proposal, requires a total of 100,000 KRW. Besides, 125,000 KRW is needed for the field investigator, and 175,000 KRW is needed for the safety investigation test, residual pesticide test, soil inspection material cost and laboratory equipment management cost.

The beginning stage of the ELFF certification system may require government subsidies. The help from the government will enable activation for the use of forest land and semi-preservation land covering about 3 million ha. It is about twice the total of Korea's agriculture land, which is 1.6 million ha. In this way, the government can take part in the effective use of land to provide clean food to our people and support the initiation of producing more NTFPs. Producers are aware of not only the need for ELFF to be developed and operated as a certification system in the future, but also the high expectation for certification persistence and certification scalability, indicating that it is feasible to maintain the sustainability of the accreditation in ELF. On the other hand, in a perception survey of ELF consumers, we found that consumers had a $21.9 \%$ price premium WTP for eco-labeled forest products. However, our regression result showed that there might be an intention for ELFF consumption when they had a decent awareness toward EFLA and when they felt satisfied with EFLA. For ELFF products to become a valid system to increase the income of forestry households, it is urgent to have a policy to enhance the credibility of certification and publicity for consumers to change their minds.

\subsection{Implications}

Through ELFA and GAP systems, we developed a direction of ELFF to make our society for sustainability. First, it is necessary to respond appropriately to the lack of sales channels and the difficulties in terms of sustainable supply by securing consumer preference and reliability, having standardized sales of small-sized stores, improving quality competitiveness, implementing recalls and organically linking with local governments. Second, it is critical to encourage the certification system as an essential process for providing safe food to the public as well as obtaining profitability means by continuously promoting, educating for and monitoring producers.

Conclusions that can be drawn from research streams related to overseas forestry product certification are as follows. First, although ELFF can be managed with more social and environmental responsibility by introducing a certification system on ELFF and ELFF can be a source of ecologically and economically sustainable income on the part of the local population, there might be a risk that the supply has problems keeping up with the market demand. Thus, the certification needs to be heavily invested in. In addition, there are some negative factors that can destroy the traditional NTFP's price market instead of ensuring environmental sustainability. Nonetheless, to realize ELF certification for sustainable management in forestry, ELFF should be considered as an urgent priority by focusing not only on the increase of forestry household income, but also on the ecological soundness of forests and common social benefits in the long term. ELFF's certification can be sustained by various instruments, including as a market-based mechanism, a regulatory mechanism through post-harvest management, and a learning mechanism related to producer knowledge of product quality. It implies that achieving the success of ELFF depends on multifaceted efforts by central and local governments as well as by the participants including producers and consumers.

\subsection{Managerial Implications}

Results of regression analysis showed that ELFA and GAP were interested in purchasing ELFF products if they were aware of the national agricultural product certification system and if they were 
satisfied with the national agricultural product certification system. This suggestes that prioritizing activities to inform ELFF products centered on consumers who prefer agricultural products in the National Agricultural Products Certification Scheme is an effective way to promote ELFF products in the future. Besides, it can be presumed that consumers have trust in ELFF products. Marketing should be centered on women. ELFF sales related to food are essential to the preference of full-time housewives. It is believed that there is room for confidence in the rigor of certification. It is time to focus on marketing to raise awareness and preference of consumers rather than focusing on producers because producers have shown satisfaction and confidence in the ELFF system through a three-year pilot project. This suggests that various publicity and marketing plans should be prepared to overcome the discrepancy between the reliability of the national certification product experienced by the consumer and trust of ELFF. In South Korea's market, Deodeok is traded with a competitive price when it is raised in the forest. Once the product is certified to be an EFLL, it costs around three times more than when it is not. Similarly, certified wild-simulated ginseng raised in the mountain is traded with a price 10 times higher.

South Korea is unique in that its agricultural and forest products are classified under a different category. This is the first study to address the certification of forest products as eco-labels in South Korea. Follow-up studies on the market status and policy analysis of introducing the ELFF brand are needed. Moreover, studies related to measures for readjustment of relevant laws for institutionalization are also required.

\subsection{Limitations}

In this study, the snowball sampling method was used for the consumer recognition survey. This technique selects subjects that the investigator considers appropriate and then invites selected participants to recommend another. This method can be said to be a kind of judgment sampling method in that subjects are selected according to the judgment of the investigator at first. Limitations are that homogeneity among subjects selected might be high for a continuous recommendation. However, such subjects have characteristics that are advantageous with the population. Since it is a sampling method commonly used in a nonparametric survey, it is judged that this method is suitable for the purpose of carrying out a consumer recognition survey of this task.

Author Contributions: Conceptualization, T.R. and J.-H.J.; methodology, T.R.; formal analysis, T.R.; investigation, T.R. and J.-H.J.; resources, T.R.; data curation, T.R.; writing—original draft preparation, T.R., J.-H.J., and J.Y.Y.; writing-review and editing, T.R., J.-H.J., and J.Y.Y.; supervision, T.R.; project administration, T.R.

Funding: This work was supported by the Soonchunhyang University Research Fund.

Acknowledgments: This study was carried out with the support of R\&D Program for Forest Science Technology (Project No. 2019159A00-1920-AB02) provided by Korea Forest Service (Korea Forestry Promotion Institute).

Conflicts of Interest: The authors declare no conflict of interest.

\section{References}

1. Loureiro, M.L.; McCluskey, J.J.; Mittelhammer, R.C. Will consumers pay a premium for eco-labeled apples? J. Consum. Aff. 2002, 36, 203-219. [CrossRef]

2. Grankvist, G.; Biel, A. The importance of beliefs and purchase criteria in the choice of eco-labeled food products. J. Environ. Psychol. 2001, 21, 405-410. [CrossRef]

3. Liu, Q.; Yan, Z.; Zhou, J. Consumer choices and motives for eco-labeled products in china: An empirical analysis based on the choice experiment. Sustainability 2017, 9, 331. [CrossRef]

4. Shanley, P.; Pierce, A.; Laird, S.; Robinson, D. Beyond Timber: Certification and Management of Non-Timber Forest Products; Center for International Forestry Research (CIFOR): Bogor Barat, Indonesia, 2008.

5. Duchelle, A.E.; Kainer, K.A.; Wadt, L.H. Is certification associated with better forest management and socioeconomic benefits? A comparative analysis of three certification schemes applied to brazil nuts in western amazonia. Soc. Nat. Resour. 2014, 27, 121-139. [CrossRef] 
6. Guedes Pinto, L.; Shanley, P.; Cota Gomes, A.; Robinson, D. Experience with ntfp certification in brazil. For. Trees Livelihoods 2008, 18, 37-54. [CrossRef]

7. Jo, J.-H.; Roh, T.; Shin, S.; Youn, Y.-C. Sustainable assets and strategies affecting the forestry household income: Empirical evidence from south korea. Sustainability 2019, 11, 3680. [CrossRef]

8. Shukri, M.; Awang Noor, A. Malaysian consumers preference and willingness to pay for environmentally certified wooden household furniture. Pertanika J. Trop. Agric. Sci. 2012, 35, 603-611.

9. Grieg-Gran, M.; Porras, I.; Wunder, S. How can market mechanisms for forest environmental services help the poor? Preliminary lessons from latin america. World Dev. 2005, 33, 1511-1527. [CrossRef]

10. Janssen, M.; Hamm, U. Product labelling in the market for organic food: Consumer preferences and willingness-to-pay for different organic certification logos. Food Qual. Prefer. 2012, 25, 9-22. [CrossRef]

11. Kilchling, P.; Hansmann, R.; Seeland, K. Demand for non-timber forest products: Surveys of urban consumers and sellers in switzerland. For. Policy Econ. 2009, 11, 294-300. [CrossRef]

12. Wilsey, D.S.; Radachowsky, J. Keeping ntfps in the forest: Can certification provide an alternative to intensive cultivation? Ethnobot. Res. Appl. 2007, 5, 45-58. [CrossRef]

13. Schmitt, J.; Pokorny, B.; Ying, L. Certification of non-timber forest products in china: Effects on food quality, forest conservation and rural development. For. Trees Livelihoods 2008, 18, 81-89. [CrossRef]

14. Yoon, Y.; Lee, H.; Lee, S.; Gwak, E.; Lee, J.; Ha, J.; Pyun, J. Good Agricultural Practices (Gap) for Agricultural Food Safety Management; KDI School of Public Policy and Management: Sejong, Korea, 2014.

15. Kim, K.-D.; Lee, J.-Y.; Sok, N.-K. Purchase behavior of environment-friendly agricultural products by housewives in seoul area. J. Korean Soc. Food Sci. Nutr. 2008, 37, 1667-1673. [CrossRef]

16. Nam, S.-M.; Noh, J.-K. A study on the uncertainty response behavior of the consumer in the purchase of the environment-friendly agricultural products. J. Mark. Stud. 2010, 18, 51-65.

17. Lee, K.-I.; Kim, S.-H.; Heo, S.-Y.; Lim, S.-J.; Kim, J.-M.; Park, I.-H. The Consumer Behavior Survey for Food 2016; Korea Rural Economic Institute: Naju, Korea, 2016.

18. Choi, M.K.; Seo, H.C.; Baek, S.H. The influence of environment-friendly agricultural products (eaps) perception of parents in chung-buk area on eaps consumption behavior. Korean J. Food Nutr. 2010, 23, 269-275.

19. Lee, H.Y.; Lee, A.J.; Kim, H.S. Effect of awareness of organic foods and corporate image on purchase intention. J. Foodserv. Manag. 2011, 14, 119-137.

20. Kim, C.-G.; Jeong, H.-K.; Lim, Y.-A.; Lee, H.-J.; Kim, Y.-G. Fostering Environment-Friendly Agriculture and Strengthening Management of Agri-Environmental Resources; Korea Rural Economic Institute: Naju, Korea, 2016.

21. Kim, W.-S. Current status on the certification system of processed organic foods in korea and foreign countries. Food Sci. Ind. 2006, 39, 20-34.

22. Shin, Y.; Hwang, Y. Directions for improving certification system of environmentally-friendly agricultural products. Korea J. Agric. Manag. Policy 2008, 35, 871-888.

23. FAO. A Scheme and Training Manual on Good Agricultural Practices (Gap) for Fruits and Vegetables; FAO (Food and Agriculture Ogranization of the United Nations): Bangkok, Thailand, 2016.

24. Hatanaka, M.; Bain, C.; Busch, L. Third-party certification in the global agrifood system. Food Policy 2005, 30, 354-369. [CrossRef]

25. EAPC. Introduction of Certification System Mark; EAPC (Environmentfriendly Agricultural Products Certification): Seoul, Korea, 2018.

26. KOPFI. Revitalizing the Management and Consumption of Clean Forest Products; KOPFI (Korea Forestry Promotion Institue): Seoul, Korea, 2019.

27. Laird, S.A.; McLain, R.J.; Wynberg, R. Wild Product Governance: Finding Policies That Work for Non-Timber Forest Products; Earthscan: London, UK, 2010.

28. Wilsey, D.S.; Hildebrand, P.E. Chamaedorea palm frond commercialization and certification considered from a smallholder livelihood system perspective. Small-Scale For. 2011, 10, 67-81. [CrossRef]

29. Pierce, A.R.; Shanley, P.; Laird, S. Non-timber forest products and certification: Strange bedfellows. For. Trees Livelihoods 2008, 18, 23-35. [CrossRef]

30. Jo, J.-H.; Roh, T. Analysis of stakeholder value chain for export activation of forest products: Focused on forest-product export specialized area. Reg. Ind. Rev. 2017, 40, 65-85. 
31. Mitchell, D.A.; Tedder, S.; Brigham, T.; Cocksedge, W.; Hobby, T. Policy gaps and invisible elbows: Ntfps in british columbia. In Wild Product Governance: Finding Policies That Work for Non-Timber Forest Products; Laird, S.A., McLain, R.J., Wynberg, R., Eds.; Earthscan: Washington, DC, USA, 2010.

32. Prothero, A.; Dobscha, S.; Freund, J.; Kilbourne, W.E.; Luchs, M.G.; Ozanne, L.K.; Thøgersen, J. Sustainable consumption: Opportunities for consumer research and public policy. J. Public Policy Mark. 2011, 30, 31-38. [CrossRef]

33. Krishnakumar, J.; Yanagida, J.F.; Anitha, V.; Balakrishnan, R.; Radovich, T.J. Non-timber forest products certification and management: A socioeconomic study among the kadars in kerala, india. Environ. Dev. Sustain. 2015, 17, 837-858. [CrossRef]

34. Yadav, M.; Dugaya, D. Non-timber forest products certification in india: Opportunities and challenges. Environ. Dev. Sustain. 2013, 15, 567-586. [CrossRef]

35. Heo, J.-N.; Kim, T.-G.; Byun, S.-H. Measuring consumers' value of quality-certificated peaches using logit and turnbull models. Korea J. Agric. Manag. Policy 2000, 27, 91-102.

36. Kwon, O.S. Estimating the willingness to pay for the non-gmo agricultural products. Korean J. Agric. Econ. 2003, 44, 111-131.

37. Lee, Y.-J.; Kim, M.; Kim, E.-H. A study on the environmentally-friendly farm produce consumer behaviour on general characteristics. Food Serv. Ind. J. 2009, 5, 103-126.

38. Haab, T.C.; McConnell, K.E. Referendum models and negative willingness to pay: Alternative solutions. J. Environ. Econ. Manag. 1997, 32, 251-270. [CrossRef]

39. Han, S.Y. Estimating the stock value of woraksan national park using turnbull distribution-free model. J. Korean Soc. For. Sci. 2007, 96, 283-289.

40. Han, S.-Y.; Lee, M.-H.; Yoo, R.-H.; Kim, J.-J. Estimating the stock value of sobaeksan national park: Application of turnbull distribution-free model. J. Korean Inst. For. Recreat. 2007, 11, 37-45.

41. Kim, J.-H. An estimation of citizen's willingness-to-pay for the quality improvement of tap water in the ulsan metropolitan area using cvm with a double-bounded choice model. Korean J. Local Gov. Stud. 2006, 10, 31-47.

(C) 2019 by the authors. Licensee MDPI, Basel, Switzerland. This article is an open access article distributed under the terms and conditions of the Creative Commons Attribution (CC BY) license (http://creativecommons.org/licenses/by/4.0/). 